\title{
Catalytic Decomposition of an Energetic Ionic Liquid Solution over Hexaaluminate Catalysts
}

\author{
Sunghoon Hong ${ }^{1}$, Sujeong Heo ${ }^{1}$, Wooram Kim ${ }^{2}$, Young Min Jo ${ }^{2}$, Young-Kwon Park ${ }^{3, *}$ \\ and Jong-Ki Jeon ${ }^{1, *}$ \\ 1 Department of Chemical Engineering, Kongju National University, Cheonan 31080, Korea; \\ karyas2@naver.com (S.H.); sujeong@smail.kongju.ac.kr (S.H.) \\ 2 Department of Environmental Science and Engineering, Kyung Hee University, Yongin 17104, Korea; \\ woojoa@hanmail.net (W.K.); ymjo@khu.ac.kr (Y.M.J.) \\ 3 School of Environmental Engineering, University of Seoul, Seoul 02504, Korea \\ * Correspondence: catalica@uos.ac.kr (Y.-K.P.); jkjeon@kongju.ac.kr (J.-K.J.); Tel.: +82-2-6490-2870 (Y.-K.P.); \\ $+82-41-521-9363$ (J.-K.J.)
}

Received: 7 November 2018; Accepted: 8 January 2019; Published: 14 January 2019

\begin{abstract}
The objective of this study was to determine the effect of a synthesis procedure of $\mathrm{Sr}$ hexaaluminate on catalytic performance during the decomposition of ionic liquid monopropellants based on ammonium dinitramide (ADN) and hydroxyl ammonium nitrate (HAN). Sr hexaaluminates were prepared via both coprecipitation and a sol-gel process. The surface area of hexaaluminate synthesized via the coprecipitation method was higher than that of hexaaluminate synthesized by the sol-gel process, and calcined at the same temperature of $1200^{\circ} \mathrm{C}$ or more. This is because of the sintering of $\alpha-\mathrm{Al}_{2} \mathrm{O}_{3}$ on the hexaaluminate synthesized via the sol-gel process, which could not be observed on the catalysts synthesized via the coprecipitation method. The hexaaluminate synthesized via coprecipitation showed a lower decomposition onset temperature during the decomposition of ADN- and HAN-based liquid monopropellants in comparison with the catalysts synthesized via the sol-gel process, and calcined at the same temperature of $1200{ }^{\circ} \mathrm{C}$ or more. This is attributed to the differences in the $\mathrm{Mn}^{3+}$ concentration and the surface area between the two hexaaluminates. Consequently, the hexaaluminate synthesized via coprecipitation which calcined above $1200{ }^{\circ} \mathrm{C}$ showed high activity during the decomposition of energetic ionic liquid monopropellants compared with the hexaaluminate synthesized via the sol-gel process.
\end{abstract}

Keywords: hexaaluminate; catalytic decomposition; ionic liquid propellant; ammonium dinitramide; hydroxyl ammonium nitrate

\section{Introduction}

Ionic liquid monopropellants, referred to as energetic ionic liquid solutions, are used for propulsion in aerospace applications. The circuit and the attitude of a satellite are controlled by small thrusters, which rely on the catalytic decomposition of hydrazine $\left(\mathrm{N}_{2} \mathrm{H}_{4}\right)$ on solid catalysts [1]. Although hydrazine is commonly used in the aerospace industry, replacing this conventional monopropellant with an eco-friendly monopropellant is crucial because of the high toxicity and high processing costs of hydrazine [1-3]. Among promising candidates, liquid monopropellants containing ammonium dinitramide $\left(\mathrm{ADN}, \mathrm{NH}_{4} \mathrm{~N}\left(\mathrm{NO}_{2}\right)_{2}\right)$ or hydroxyl ammonium nitrate ( $\mathrm{HAN}, \mathrm{NH}_{3} \mathrm{OHNO}_{3}$ ) are considered the most attractive alternatives [4]. Recently, ADN-based liquid monopropellants consisting of an ADN aqueous solution, methanol, and ammonia were commercialized [5]. An HAN-based liquid monopropellant was also used in aqueous solutions [6,7]. ADN and HAN are highly energetic compounds, and the decomposition of ADN- and HAN-based 
liquid monopropellants does not generate halogen compounds. With these advantages, ADN- and HAN-based liquid monopropellants attracted attention as green propellants [8].

Because ADN- and HAN-based liquid propellants have high moisture content, preheating is required up to the decomposition initiation temperature in order to activate decomposition in the thruster [9]. Once ADN- and HAN-based liquid propellants are sufficiently heated above a certain temperature, known as the "decomposition onset temperature", explosive decomposition in a thruster occurs continuously. However, because the storage space of the energy source in a satellite is limited, the energy consumption should be minimized. In order to address this issue, the decomposition onset temperature should be reduced by means of catalytic decomposition until it is as low as possible. Therefore, developing effective catalysts that can accelerate the decomposition of the ADN- and HAN-based monopropellants at low temperatures is the key to meeting this challenge.

Meanwhile, when a liquid propellant begins to decompose in a satellite thruster, the temperature of the catalyst bed rises to $1200{ }^{\circ} \mathrm{C}$ or higher $[10,11]$. Because the liquid propellant is used to control the satellite attitude, decomposition of the propellant occurs intermittently and repeatedly. Therefore, a catalyst with high heat resistance is essential. That is, catalysts used to decompose a liquid propellant in a satellite thruster must meet simultaneously the requirements of high activity at a low temperature and high heat resistance.

Despite the lack of studies on the catalytic decomposition of ionic liquid monopropellants, some precious-metal catalysts supported on alumina, such as $\mathrm{Pt} / \mathrm{Al}_{2} \mathrm{O}_{3}, \mathrm{Ir} / \mathrm{Al}_{2} \mathrm{O}_{3}-\mathrm{La}_{2} \mathrm{O}_{3}$, and $\mathrm{CuO} / \mathrm{Al}_{2} \mathrm{O}_{3}-\mathrm{La}_{2} \mathrm{O}_{3}$, were reported in related fields [2]. Aluminum oxide can be prepared in different phases, for instance, the dehydration of boehmite at $300-500{ }^{\circ} \mathrm{C}$ yields $\gamma-\mathrm{Al}_{2} \mathrm{O}_{3}$, while, in a temperature range of $700-800{ }^{\circ} \mathrm{C}$, it produces $\delta-\mathrm{Al}_{2} \mathrm{O}_{3}$; at a higher temperature range of $900-1000{ }^{\circ} \mathrm{C}$, it gives $\theta-\mathrm{Al}_{2} \mathrm{O}_{3}$; and, at $1000-1200{ }^{\circ} \mathrm{C}$, it produces $\alpha-\mathrm{Al}_{2} \mathrm{O}_{3}$ [12]. Catalysts that improve thermal stability at high temperatures exceeding $1200^{\circ} \mathrm{C}$ were subject to continual study, and hexaaluminates attracted much attention as highly heat-resistant catalysts $[13,14]$. In particular, when $\mathrm{Sr}$ or Ba is added into the hexaaluminate structure, it reportedly has high heat resistance even at temperatures of $1200{ }^{\circ} \mathrm{C}$ or higher $[15,16]$. Ir, $\mathrm{Pt}, \mathrm{Cu}$, and $\mathrm{Rh}$ supported on hexaaluminates were reported as effective catalysts for the decomposition of ADN- and HAN-based liquid monopropellants [17,18]. However, the effects of the synthesis procedure and heat treatment of a hexaaluminate catalyst on the decomposition performance of an ionic liquid propellant remain to be studied.

In this study, Sr hexaaluminate samples were prepared via both coprecipitation and a sol-gel process. The effects of the synthesis procedure and heat treatment on the physicochemical properties of the catalyst samples were investigated using X-ray diffraction (XRD), $\mathrm{N}_{2}$-adsorption, X-ray photoelectron spectroscopy (XPS), X-ray fluorescence (XRF), and $\mathrm{H}_{2}$ temperature-programmed reduction (TPR). The catalytic performance during the decomposition of ADN- and HAN-based liquid propellants was evaluated using a batch reactor.

\section{Results and Discussion}

\subsection{Characterization of Hexaaluminates}

The $\mathrm{N}_{2}$-adsorption isotherms of the $\mathrm{Sr}$ hexaaluminate catalysts synthesized via the sol-gel process which calcined at a temperature of $1000{ }^{\circ} \mathrm{C}$ or lower (Figure 1) showed a type IV(a) isotherm in the International Union of Pure and Applied Chemistry (IUPAC) classification [19]; furthermore, they exhibited the $\mathrm{H} 3$ type of hysteresis loop, stemming from the pore network, which consists of macropores that are not entirely filled with pore condensate [19]. In the case of the Sr hexaaluminate catalysts synthesized via the coprecipitation method which calcined at a temperature of $1000{ }^{\circ} \mathrm{C}$ or lower, the characteristics of the $\mathrm{N}_{2}$-physisorption isotherm did not differ much from those of the $\mathrm{N}_{2}$-adsorption isotherm of the $\mathrm{Sr}$ hexaaluminate catalysts produced via the sol-gel process (Figure 2). With regards to the catalysts calcined at $1000{ }^{\circ} \mathrm{C}$ or lower, the surface area $\left(\mathrm{S}_{\mathrm{BET}}\right)$ and pore volume $\left(\mathrm{V}_{\mathrm{p}}\right)$ of the catalyst produced via the sol-gel process were much larger than those of the catalyst prepared 
via coprecipitation (Table 1). Tian et al. suggested that one of the advantages of the sol-gel method is the low-temperature processing of complex oxides due to the homogeneous mixing of components at a molecular level, thereby enhancing the specific surface area [20]. The results of our study are also in good agreement with their suggestion.

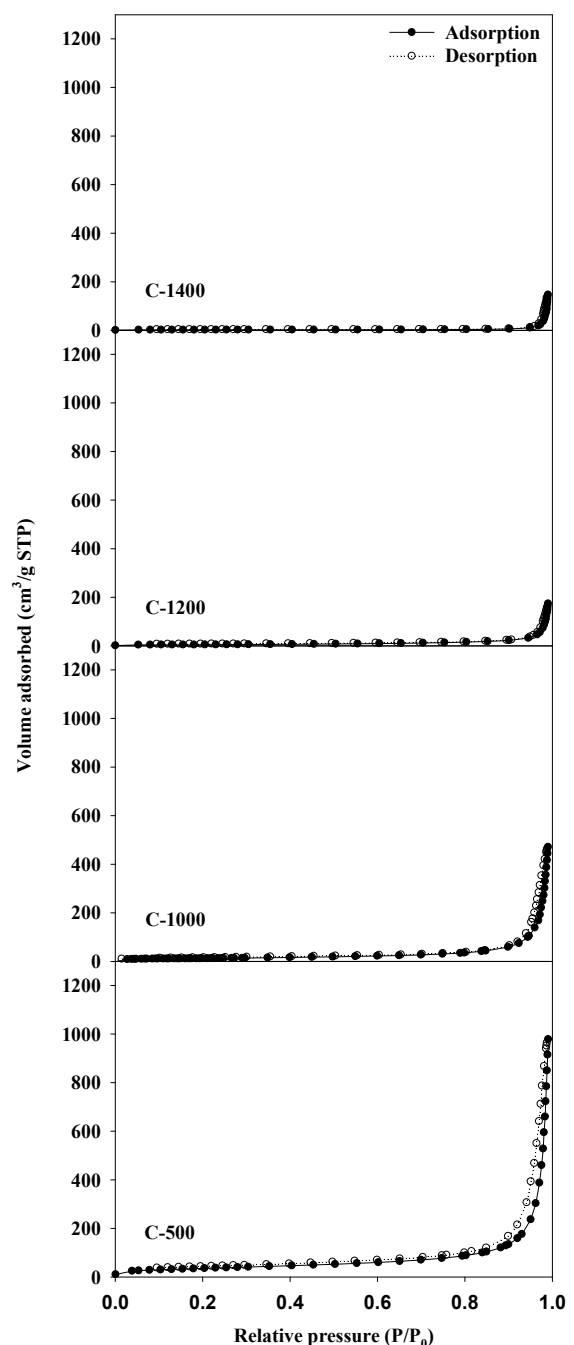

(a)

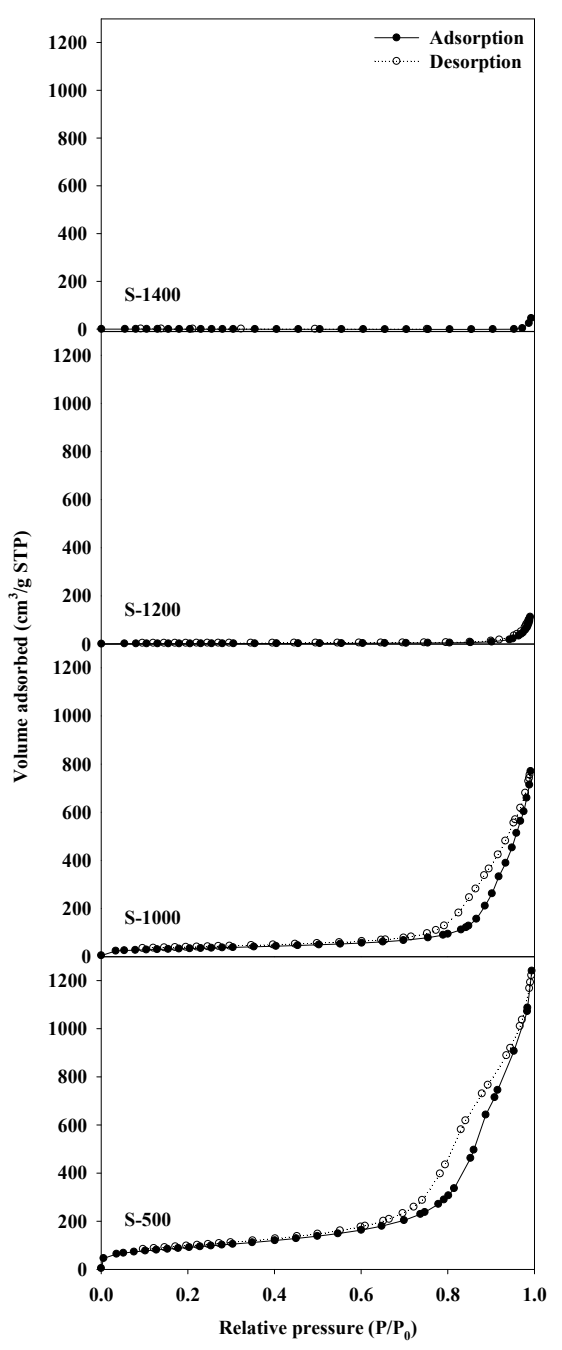

(b)

Figure 1. $\mathrm{N}_{2}$-adsorption-desorption isotherms of hexaaluminates prepared via (a) coprecipitation method, and (b) the sol-gel procedure.

Table 1. Textural properties of catalysts prepared via coprecipitation and the sol-gel procedure.

\begin{tabular}{ccccc}
\hline Catalysts & Synthesis Method & Calcination Temperature $\left({ }^{\circ} \mathbf{C}\right)$ & $\mathbf{S}_{\text {BET }}\left(\mathbf{m}^{\mathbf{2}} / \mathbf{g}\right)^{\mathbf{a}}$ & $\mathbf{V}_{\mathbf{p}}\left(\mathbf{c m}^{\mathbf{3}} / \mathbf{g}\right)^{\mathbf{b}}$ \\
\hline C-1400 & Coprecipitation & 1400 & 8 & 0.19 \\
C-1200 & Coprecipitation & 1200 & 17 & 0.23 \\
C-1000 & Coprecipitation & 1000 & 46 & 0.68 \\
C-500 & Coprecipitation & 500 & 129 & 1.39 \\
\hline S-1400 & Sol-gel & 1400 & $<1$ & 0.05 \\
S-1200 & Sol-gel & 1200 & 7 & 0.16 \\
S-1000 & Sol-gel & 1000 & 119 & 1.12 \\
S-500 & Sol-gel & 500 & 327 & 1.80 \\
\hline
\end{tabular}

${ }^{a} \mathrm{~S}_{\mathrm{BET}}$ : Surface area calculated using the Brunauer-Emmett-Teller $(\mathrm{BET})$ method; ${ }^{\mathrm{b}} \mathrm{V}_{\mathrm{p}}$ : total pore volume estimated from the isotherm at $\mathrm{P} / \mathrm{P}_{0}=0.99$. 
Nitrogen adsorption isotherms of $\mathrm{Sr}$ hexaaluminate catalysts which calcined at a temperature higher than $1200{ }^{\circ} \mathrm{C}$ showed a type II physisorption isotherm in the IUPAC classification, indicating that the catalysts were converted to nonporous or macroporous material structures during the high-temperature treatment [19]. The specific surface area and pore volume of the catalyst prepared via the sol-gel process and via the coprecipitation method decreased considerably as the calcination temperature increased (Table 1). At temperatures exceeded $1200{ }^{\circ} \mathrm{C}$, the pore structure collapsed because of the sintering of the particles, and the specific surface area decreased. In particular, the decreased specific surface area of the Sr hexaaluminate catalyst prepared via the sol-gel process was more remarkable in comparison with the Sr hexaaluminate catalyst synthesized via the coprecipitation method. As a result, the specific surface area of the Sr hexaaluminate catalyst produced via the sol-gel process becomes smaller than that of the catalyst prepared via coprecipitation, heat-treated at the same temperature of $1200^{\circ} \mathrm{C}$ or higher.

X-ray diffraction (XRD) patterns of $\mathrm{Sr}$ hexaaluminate prepared via coprecipitation are shown in Figure 2. The XRD patterns of the calcined catalysts at $500{ }^{\circ} \mathrm{C}$ and $1000{ }^{\circ} \mathrm{C}$ were found to be the $\gamma$ alumina phase and the $\theta$ alumina phase, respectively [21,22]. However, the catalysts exhibited a predominance of hexaaluminate after calcination at 1200 and $1400^{\circ} \mathrm{C}$. A small amount of $\mathrm{LaAlO}_{3}$ was detected in the XRD patterns of the catalysts synthesized via the coprecipitation method (JCPDS \#31-0022), which is in agreement with previous studies by Kim et al. [23]. The presence of $\mathrm{LaAlO}_{3}$ was ascribed to the solid-state reaction between the aluminum precursor and the lanthanum precursor.

In the case of the catalyst manufactured via the sol-gel process, the hexaaluminate structure was also readily observable after calcination at a temperature of $1200{ }^{\circ} \mathrm{C}$ or higher (Figure 2). Regardless of the synthesis procedure, a high-temperature treatment of $1200{ }^{\circ} \mathrm{C}$ or more was necessary to obtain a hexaaluminate structure. In particular, an XRD pattern in a range of 32 to $36^{\circ}$ of the hexaaluminate sample prepared via the coprecipitation method showed the single hexaaluminate phase (Figure 2a) [16]. On the other hand, in the same range, the XRD pattern of the catalyst prepared via the sol-gel process exhibited the presence of the $\alpha-\mathrm{Al}_{2} \mathrm{O}_{3}$ phase after calcination at $1400{ }^{\circ} \mathrm{C}$ (JCPDS \#46-1212). Machida et al. stated that a single hexaaluminate phase is necessary to provide a large surface area in the case of hexaaluminate catalysts used for high-temperature decomposition [16]. In addition, it was reported that the thermal stability of Sr hexaaluminate at a high temperature was diminished because of the additional formation of another phase over the catalyst $[16,24]$. Comparing the catalysts calcined at $1400{ }^{\circ} \mathrm{C}$, it was confirmed that the catalyst prepared via the sol-gel process had a lower specific surface area than that of the catalyst prepared via the coprecipitation method. The presence of the $\alpha-\mathrm{Al}_{2} \mathrm{O}_{3}$ phase in this catalyst prepared via the sol-gel process is thought to be responsible for the decrease of the specific surface area.

The composition of the catalyst surface as confirmed by X-ray fluorescence (XRF) analysis is depicted in Table 2. In the case of hexaaluminate prepared via the coprecipitation method, the ratios of $\mathrm{Mn}, \mathrm{Sr}$, and La to $\mathrm{Al}$ were approximately three times higher than those of hexaaluminate produced via the sol-gel process. This means that the concentration of cross-linked Al was high inside the spinel block with a mirror surface in the hexaaluminate sample prepared via the coprecipitation method. Therefore, hexaaluminate prepared via coprecipitation had a more stable structure, which was also confirmed by XRD analysis.

Regardless of the synthesis procedure used, the Sr concentration increased rapidly as the calcination temperature increased; this was ascribed to the migration of Sr from the inside of the hexaaluminate structure to the surface at a high temperature. Meanwhile, the surface compositions of the catalysts calcined at 1200 and $1400{ }^{\circ} \mathrm{C}$ were similar to that of $\mathrm{Sr}$ hexaaluminate $\left(\mathrm{Sr}_{0.8} \mathrm{La}_{0.2} \mathrm{Mn}_{11} \mathrm{O}_{19}\right)$, which is well known in the literature $[16,23,24]$. 


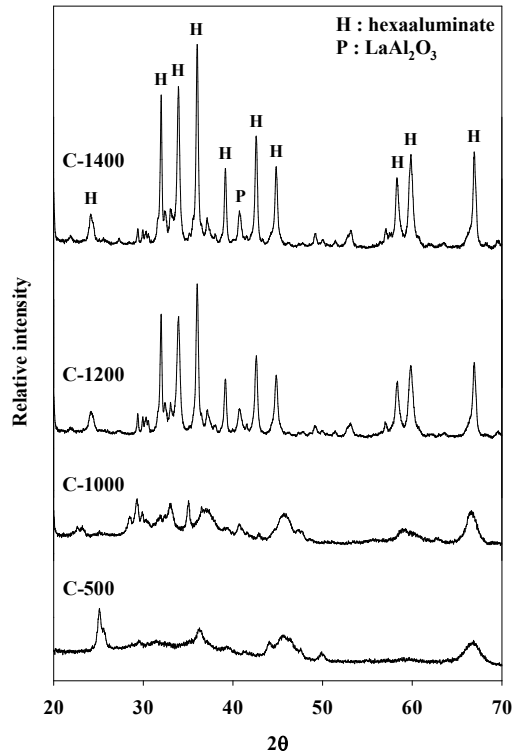

(a)

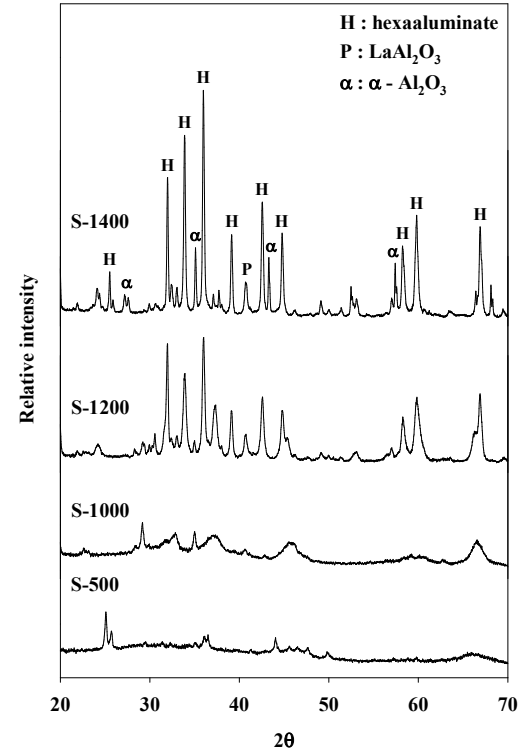

(b)

Figure 2. X-ray diffraction (XRD) patterns of catalysts prepared via the (a) coprecipitation method, and (b) sol-gel procedure.

Table 2. Surface composition of hexaaluminates prepared via coprecipitation and the sol-gel procedure.

\begin{tabular}{|c|c|c|c|}
\hline Catalysts & \multicolumn{2}{|c|}{ wt (\%) } & Element/Al \\
\hline \multirow{4}{*}{ C-1400 } & $\mathrm{Al}_{2} \mathrm{O}_{3}$ & 21.1 & - \\
\hline & $\mathrm{MnO}$ & 21.7 & 0.37 \\
\hline & $\mathrm{SrO}$ & 40.6 & 0.47 \\
\hline & $\mathrm{La}_{2} \mathrm{O}_{3}$ & 12.4 & 0.09 \\
\hline \multirow{4}{*}{ C-1200 } & $\mathrm{Al}_{2} \mathrm{O}_{3}$ & 23.2 & - \\
\hline & $\mathrm{MnO}$ & 23.7 & 0.37 \\
\hline & $\mathrm{SrO}$ & 35.2 & 0.37 \\
\hline & $\mathrm{La}_{2} \mathrm{O}_{3}$ & 12.8 & 0.09 \\
\hline \multirow{4}{*}{ C-1000 } & $\mathrm{Al}_{2} \mathrm{O}_{3}$ & 26.6 & - \\
\hline & $\mathrm{MnO}$ & 25.3 & 0.34 \\
\hline & $\mathrm{SrO}$ & 24.2 & 0.26 \\
\hline & $\mathrm{La}_{2} \mathrm{O}_{3}$ & 13.8 & 0.08 \\
\hline \multirow{4}{*}{ C-500 } & $\mathrm{Al}_{2} \mathrm{O}_{3}$ & 25.8 & - \\
\hline & $\mathrm{MnO}$ & 25.5 & 0.35 \\
\hline & $\mathrm{SrO}$ & 29.6 & 0.28 \\
\hline & $\mathrm{La}_{2} \mathrm{O}_{3}$ & 13.5 & 0.08 \\
\hline \multirow{4}{*}{ S-1400 } & $\mathrm{Al}_{2} \mathrm{O}_{3}$ & 48.9 & - \\
\hline & $\mathrm{MnO}$ & 15.9 & 0.12 \\
\hline & $\mathrm{SrO}$ & 23.3 & 0.12 \\
\hline & $\mathrm{La}_{2} \mathrm{O}_{3}$ & 9.3 & 0.03 \\
\hline \multirow{4}{*}{ S-1200 } & $\mathrm{Al}_{2} \mathrm{O}_{3}$ & 54.2 & - \\
\hline & $\mathrm{MnO}$ & 16.5 & 0.11 \\
\hline & $\mathrm{SrO}$ & 17.8 & 0.08 \\
\hline & $\mathrm{La}_{2} \mathrm{O}_{3}$ & 8.5 & 0.02 \\
\hline \multirow{4}{*}{ S-1000 } & $\mathrm{Al}_{2} \mathrm{O}_{3}$ & 60.6 & - \\
\hline & $\mathrm{MnO}$ & 16.5 & 0.10 \\
\hline & $\mathrm{SrO}$ & 11.1 & 0.05 \\
\hline & $\mathrm{La}_{2} \mathrm{O}_{3}$ & 8.6 & 0.02 \\
\hline \multirow{4}{*}{ S-500 } & $\mathrm{Al}_{2} \mathrm{O}_{3}$ & 63.8 & - \\
\hline & $\mathrm{MnO}$ & 16.0 & 0.09 \\
\hline & $\mathrm{SrO}$ & 7.9 & 0.03 \\
\hline & $\mathrm{La}_{2} \mathrm{O}_{3}$ & 8.2 & 0.02 \\
\hline
\end{tabular}


The temperature-programmed reduction (TPR) profiles of the Sr hexaaluminate catalysts prepared via coprecipitation, with a distinct reduction peak around $340^{\circ} \mathrm{C}$ and a broad peak around $700{ }^{\circ} \mathrm{C}$, are shown in Figure 3. The peak around $340^{\circ} \mathrm{C}$ was attributed to the reduction of the manganese ions $\left(\mathrm{Mn}^{3+}\right)$ located at the aluminum interstitial site adjacent to the mirror plane, which are easily reduced by the rapid diffusion of $\mathrm{H}_{2}$ between the spinel blocks [25]. The peak around $700{ }^{\circ} \mathrm{C}$ corresponds to the reduction of the $\mathrm{Mn}^{3+}$ ions arranged in the spinel block, which were more difficult to reduce. The former ions are known to be the most reactive manganese species. The temperature-programmed reduction profiles of the catalysts produced via the sol-gel process showed smaller reduction peaks at a higher temperature than those prepared by coprecipitation. The difference in reduction temperature indicates that $\mathrm{Mn}^{3+}$ ions were positioned at different distances from the mirror plane. On the other hand, the difference in the peak area discloses that different numbers of $\mathrm{Mn}^{3+}$ ions arose in the hexaaluminate lattice. According to the TPR analysis, the Sr hexaaluminate catalyst prepared via coprecipitation contained more reactive $\mathrm{Mn}^{3+}$ ions than that prepared via the sol-gel process.

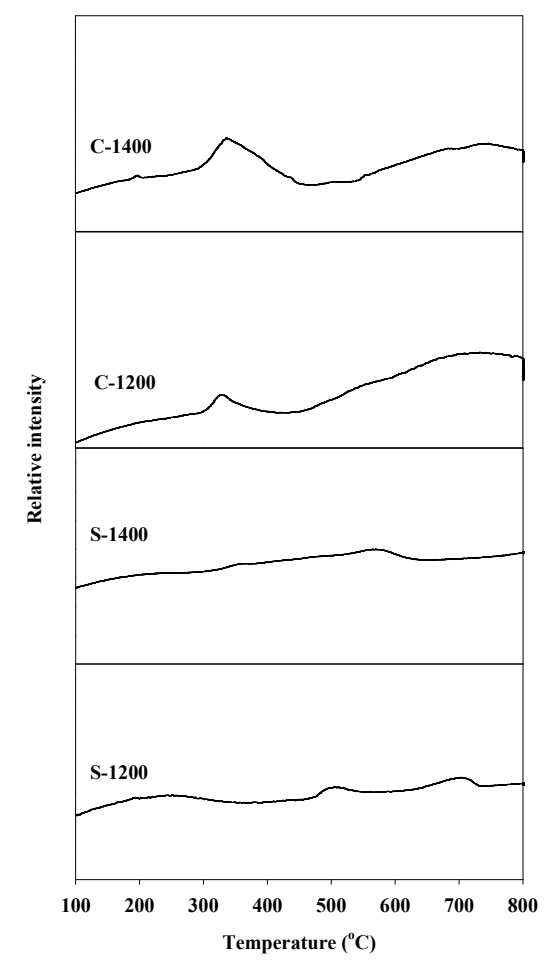

Figure 3. $\mathrm{H}_{2}$ temperature-programmed reduction (TPR) profiles of hexaaluminate catalysts prepared via coprecipitation and the sol-gel process.

An X-ray photoelectron spectroscopy (XPS) analysis was conducted to observe the oxidation state of manganese species present on the surface of the catalyst, and of the oxygen present on the surface of the catalyst and in the spinel block lattice. The Mn2 $\mathrm{p}_{3 / 2}$ and O1s XPS spectra of hexaaluminate catalysts prepared via the coprecipitation and sol-gel methods are presented in Figures 4 and 5, respectively. The Mn2 $\mathrm{p}_{3 / 2}$ spectra showed a band between 641.2 and $642.5 \mathrm{eV}$. This is the binding energy of the $\mathrm{Mn}^{2+}$ and $\mathrm{Mn}^{3+}$ oxidation states over the hexaaluminates, a finding consistent with the results of Arai et al. [15]. In the case of C-500 and C-1000 catalysts, Mn2 $\mathrm{p}_{3 / 2}$ peaks were observed around $642.0 \mathrm{eV}$, which is the reported value for $\mathrm{MnO}_{2}$ [26]. When the calcination temperature was increased above $1200{ }^{\circ} \mathrm{C}$, the binding energy values for the $\mathrm{Mn} 2 \mathrm{p}_{3 / 2}$ peaks shifted to near $641.0 \mathrm{eV}$, which is a location between that of the $\mathrm{Mn}_{2} \mathrm{p}_{3 / 2}$ in $\mathrm{MnO}$ and $\mathrm{Mn}_{2} \mathrm{O}_{3}$. Similar trends were observed for the hexaaluminate catalysts prepared via the sol-gel method.

On the other hand, the O1s spectra were divided into two bands. The band appearing near $530 \mathrm{eV}$ corresponds to the adsorbed oxygen species on the surface, while the band between 520 and 
$525 \mathrm{eV}$ was a result of the lattice oxygen existing in the spinel block [27]. With regards to the catalysts synthesized via the sol-gel process, the lattice oxygen band increased with an increase in the calcination temperature, and the band due to lattice oxygen in this case was more apparent than that when the coprecipitation method was used.

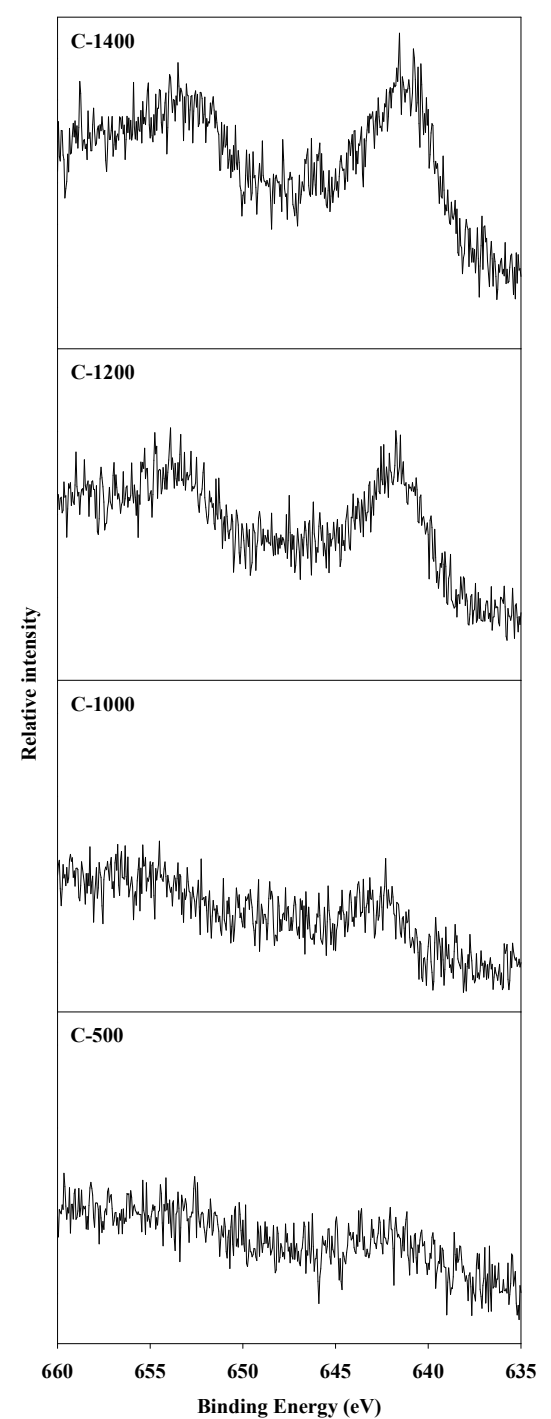

(a)

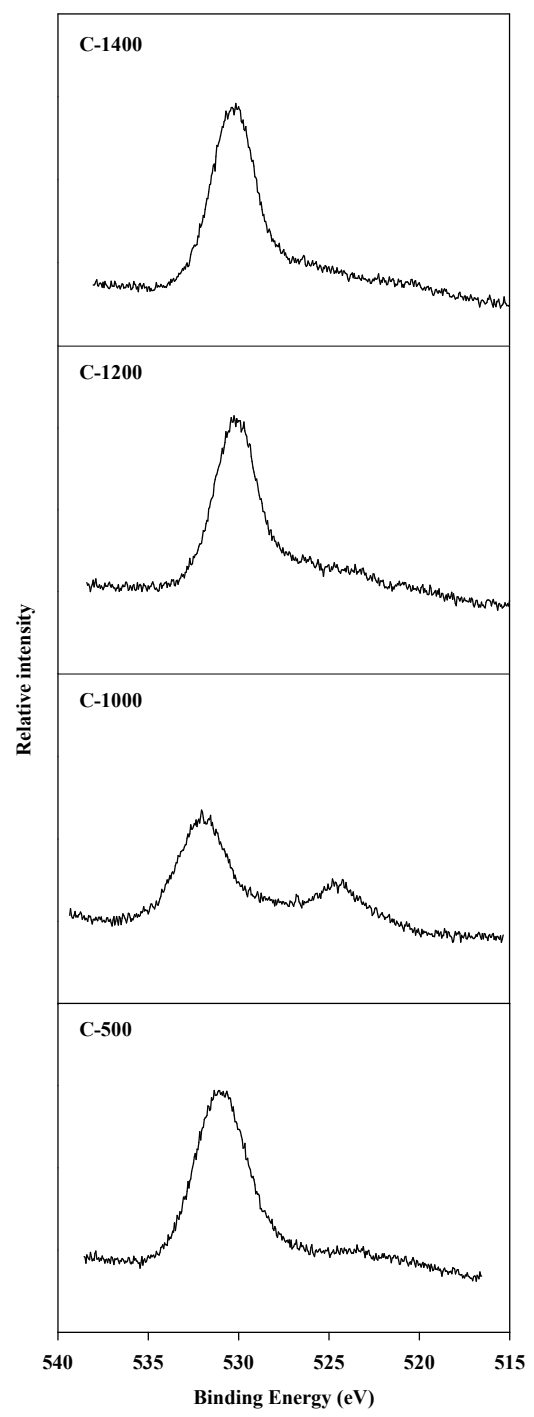

(b)

Figure 4. X-ray photoelectron spectroscopy (XPS) spectra for hexaaluminate prepared via the

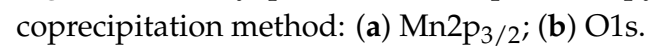




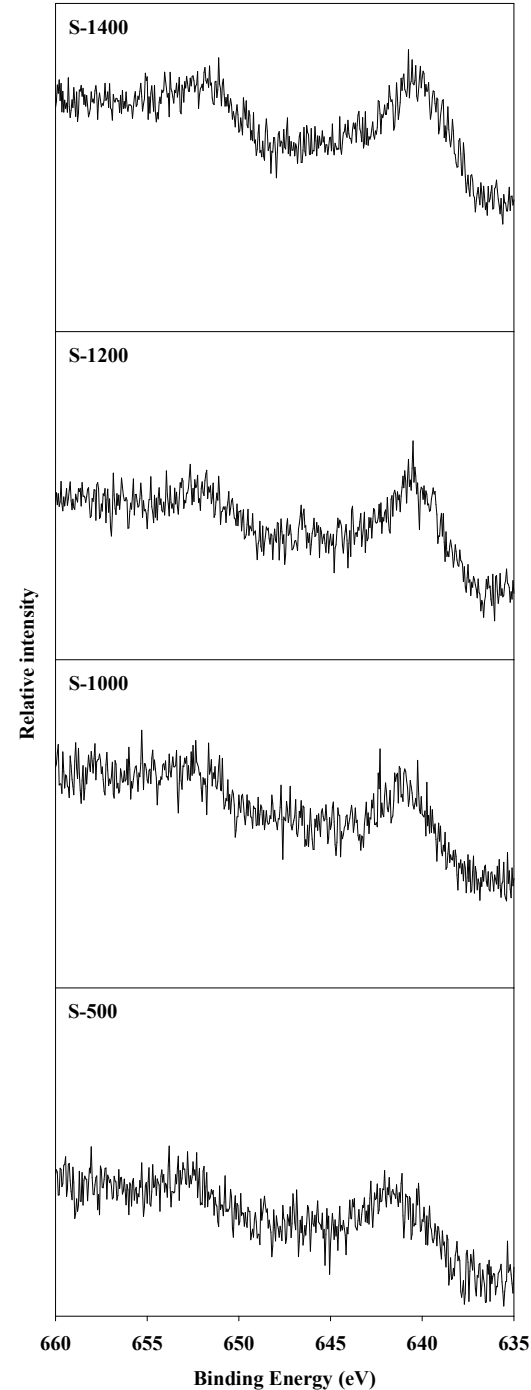

(a)

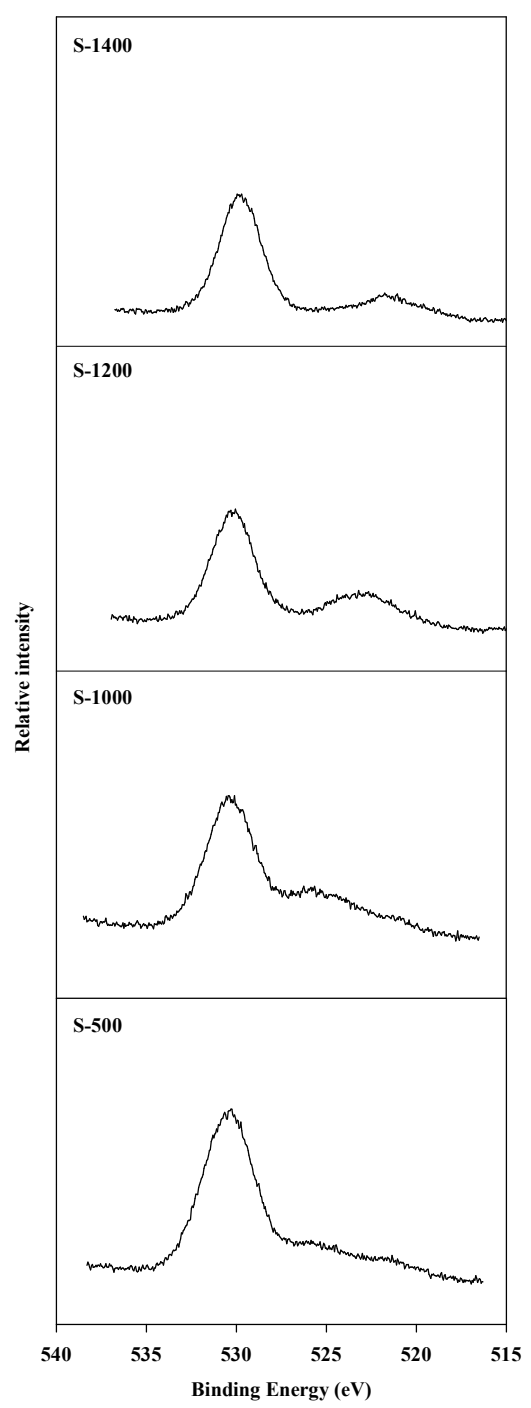

(b)

Figure 5. XPS spectra for hexaaluminate prepared via the sol-gel procedure: (a) $\mathrm{Mn}_{2} \mathrm{p}_{3 / 2}$; (b) O1s.

\subsection{Catalytic Decomposition of the Liquid Monopropellants}

The thermal decomposition results of the ADN- and HAN-based liquid monopropellants without a catalyst (Figure 6) showed that the ADN- and HAN-based liquid monopropellants were decomposed in one step. During the decomposition of the liquid monopropellants, the temperature of the catalyst increased sharply because of a strong exothermic reaction. The point at which the temperature started to increase is referred to as the decomposition onset temperature $\left(T_{\text {dec }}\right)[28,29]$. In addition, the gas product that formed abruptly during the decomposition process was accompanied by an abrupt pressure increase. With regards to thermal decomposition without a catalyst in the decomposition reactions of the $\mathrm{ADN}$ - and HAN-based liquid monopropellants, the decomposition onset temperatures were $167.0^{\circ} \mathrm{C}$ and $124.7^{\circ} \mathrm{C}$, respectively.

Typical examples of the results of the catalytic decomposition of the ADN- and HAN-based liquid monopropellants are shown in Figure 6. During decomposition using the catalysts, the decomposition onset temperature was much lower than that during thermal decomposition. The lower the decomposition onset temperature is, the better the catalytic activity will be during the decomposition of the liquid monopropellants [28,29]. 


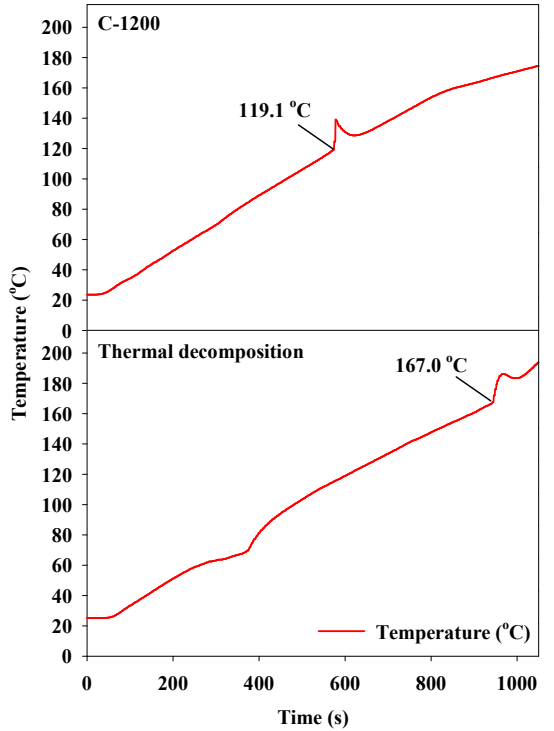

(a)

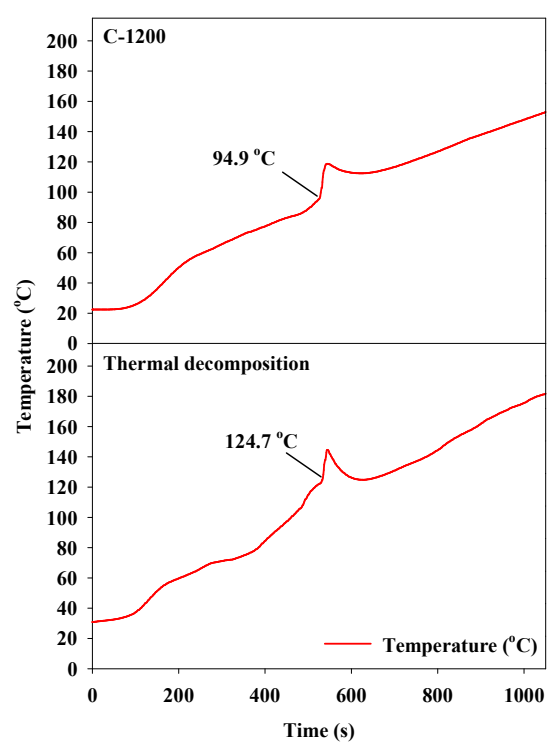

(b)

Figure 6. Catalytic decomposition over hexaaluminate prepared via the coprecipitation method: (a) ammonium dinitramide (ADN)-based liquid monopropellant; (b) hydroxyl ammonium nitrate (HAN)-based liquid monopropellant.

The decomposition onset temperatures $\left(\mathrm{T}_{\mathrm{dec}}\right)$ of the ADN- and HAN-based liquid monopropellants are presented in Table 3. In the case of catalytic decomposition of the ADN-based liquid monopropellant over the $\mathrm{Sr}$ hexaaluminate catalysts after calcination at $1000{ }^{\circ} \mathrm{C}$ or lower, the decomposition onset temperature over the Sr hexaaluminate catalysts synthesized via the sol-gel process was much lower than that over the catalysts prepared via the coprecipitation method. In particular, the S-1000 catalyst showed the lowest onset temperature of $92.1^{\circ} \mathrm{C}$. This had the effect of lowering the decomposition onset temperature by $74.9^{\circ} \mathrm{C}$ compared with thermal decomposition.

Table 3. Decomposition onset temperature during the decomposition of an ammonium dinitramide (and)-based liquid monopropellant.

\begin{tabular}{cc}
\hline Catalysts & $\mathbf{T}_{\mathbf{d e c}}\left({ }^{\circ} \mathbf{C}\right)^{\mathbf{a}}$ \\
\hline Thermal decomposition & 167.0 \\
\hline C-1400 & 119.8 \\
C-1200 -1000 & 119.1 \\
C-500 & 107.8 \\
S-1400 & 98.4 \\
S-1200 -1000 & 129.1 \\
S-500 & 130.7 \\
\hline${ }^{\text {a }} \mathrm{T}_{\mathrm{d}}:$ Decomposition onset temperature.
\end{tabular}

However, in the case of the catalyst calcined at a temperature of $1200{ }^{\circ} \mathrm{C}$ or higher, the order of the low-temperature activity of the catalysts differed from that over the catalysts calcined at a temperature of $1000{ }^{\circ} \mathrm{C}$ or lower. During the catalytic decomposition of the ADN-based liquid monopropellant over the Sr hexaaluminate catalysts after calcination at $1200{ }^{\circ} \mathrm{C}$ or higher, the decomposition onset temperature over the catalysts prepared voa the coprecipitation method was lower than that over the catalysts prepared via the sol-gel process. It was confirmed that the specific surface area of the Sr hexaaluminate catalyst prepared via the sol-gel process became smaller than that of the catalyst prepared via coprecipitation when using a catalyst heat-treated at temperatures exceeding $1200^{\circ} \mathrm{C}$. 
Moreover, the Sr hexaaluminate catalysts prepared via coprecipitation (the C-1200 and C-1400 catalysts) contained more reactive $\mathrm{Mn}^{3+}$ ions and a greater amount of surface oxygen compared with the catalysts prepared via the sol-gel process (S-1200 and S-1400), which corresponds with the results of the $\mathrm{H}_{2}$-TPR analysis.

The order of catalytic activity during the decomposition reaction of the HAN-based liquid monopropellant did not differ significantly from that of the ADN-based liquid monopropellant (Table 4). The decomposition onset temperature during the thermal reaction of the HAN-based liquid monopropellant was $124.7^{\circ} \mathrm{C}$. Using the Sr hexaaluminate catalysts, the decomposition onset temperature could be lowered to $94.9^{\circ} \mathrm{C}$. Recently, Esparza et al. reported that the use of an iridium/rhodium foam catalyst decreased the decomposition temperature of HAN solution by over $60{ }^{\circ} \mathrm{C}$ [30]. Because the HAN concentration (24 wt.\%) of the HAN-solution that they used is about one-third that of the raw materials of this study, it is unreasonable to compare the effects of the catalysts with each other. Nevertheless, it is notable that Sr hexaaluminate without noble metal can lower the decomposition temperature of an HAN-based monopropellant. For the catalyst calcined at the same temperature of $1200{ }^{\circ} \mathrm{C}$, the catalyst prepared via the coprecipitation method showed a lower onset temperature than that of the catalyst prepared via the sol-gel process. This means that if the catalysts calcined at temperatures of $1200{ }^{\circ} \mathrm{C}$ are compared, the catalyst prepared via coprecipitation was superior to the catalyst prepared via the sol-gel process for low-temperature activity during the decomposition of an HAN-based liquid monopropellant. When the ADN- and HAN-based liquid monopropellant decomposition reactions were applied to the thruster of a satellite, the temperature of the catalyst bed rose intermittently to more than $1200{ }^{\circ} \mathrm{C}$ [31]. Therefore, the activity of the catalyst calcined at a temperature of $1200^{\circ} \mathrm{C}$ or more is an important measure. Consequently, the $\mathrm{Sr}$ hexaaluminate catalyst prepared via the coprecipitation method was superior to the catalyst prepared via the sol-gel process with regards to meeting the high heat resistance and low-temperature activity requirements during the decomposition of ionic liquid propellants.

Table 4. Decomposition onset temperature during the catalytic decomposition of a hydroxyl ammonium nitrate (HAN)-based liquid monopropellant.

\begin{tabular}{cc}
\hline Catalysts & $\mathbf{T}_{\mathbf{d e c}}\left({ }^{\circ} \mathbf{C}\right)^{\mathbf{a}}$ \\
\hline Thermal decomposition & 124.7 \\
C-1200 & 94.9 \\
S-1200 & 101.8 \\
\hline a $\mathrm{T}_{\text {decomposition onset temperature }}$
\end{tabular}

a $\mathrm{T}_{\mathrm{dec}}$ : Decomposition onset temperature.

\subsection{Repeatability Experiments in Catalytic Decomposition of the ADN-Based Liquid Monopropellants}

The decomposition of the ADN-based liquid propellant was repeated four times using the pellet-type C-1200 catalyst. The decomposition onset temperature did not increase considerably during the four-time repetitive decomposition of the ADN-based propellant (Figure 7). The XRD pattern of the spent C-1200 catalyst was compared with that of the fresh catalyst (Figure 8), and the spent C-1200 catalyst maintained the hexaaluminate structure well and no difference from the fresh catalyst was found. Consequently, the pellet-type C-1200 catalyst could be recovered and reused. 


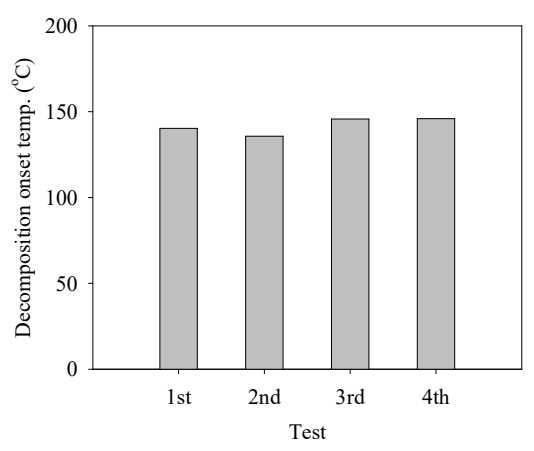

Figure 7. Decomposition onset temperature during the decomposition of the ADN-based liquid monopropellant over the pellet-type C-1200 catalyst for four repetitive tests.

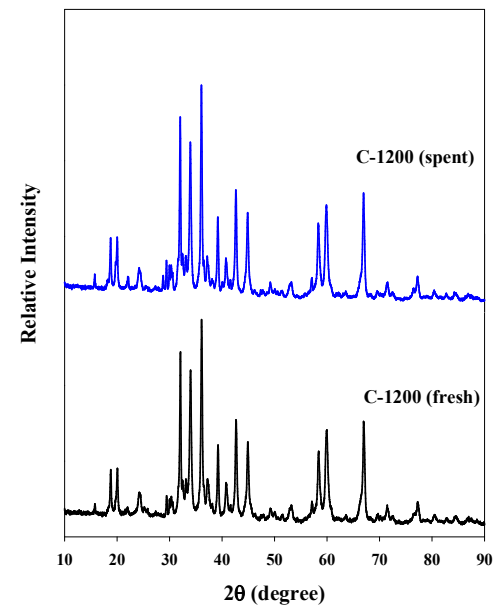

Figure 8. XRD patterns of the fresh C-1200 and spent C-1200 catalysts.

\section{Materials and Methods}

\subsection{Synthesis of Hexaaluminates}

Sr hexaaluminates with the composition of $\mathrm{Sr}_{0.8} \mathrm{La}_{0.2} \mathrm{MnAl}_{11} \mathrm{O}_{19}$ were prepared using either a well-known precipitation method or the sol-gel process $[17,22]$. The procedure used to prepare the catalyst via the precipitation method is as follows [17]: nitrates of lanthanum, aluminum, manganese, and strontium were weighed to meet the composition requirements. Precursors except for the aluminum nitrate were mixed with $300 \mathrm{~mL}$ of distilled water. $\mathrm{HNO}_{3}$ was added to adjust the $\mathrm{pH}$ to 1 , after which the aluminum nitrate was added and the solution was stirred to result in a precursor mixture solution. To $200 \mathrm{~mL}$ of distilled water was added $64.06 \mathrm{~g}$ of ammonium carbonate to prepare a $1 \mathrm{M}$ ammonium carbonate solution. After adding $200 \mathrm{~mL}$ of the ammonium carbonate solution to a four-necked flask, a $1 \mathrm{M} \mathrm{NH}_{4} \mathrm{OH}$ solution and the precursor mixture solution were prepared in a separating funnel, and a $\mathrm{pH}$ meter, a thermocouple, and a mechanical stirrer were installed. The temperature of the heating mantle was maintained at $60{ }^{\circ} \mathrm{C}$ with the stirring speed of the impeller being maintained at $300 \mathrm{rpm}$, and the precursor mixture solution was added in a dropwise manner (100 $\mathrm{mL} / \mathrm{min})$ to the aqueous solution of ammonium carbonate. The $\mathrm{pH}$ of the mixture of the precursor and ammonium carbonate solution was controlled with $1 \mathrm{M} \mathrm{NH}_{4} \mathrm{OH}$ solution to hold the $\mathrm{pH}$ at 7-8. The precipitate was washed and vacuum filtration was repeated three times to remove the nitrates and excess ammonium carbonate. The powder was then dried in an oven at $110{ }^{\circ} \mathrm{C}$ for $24 \mathrm{~h}$. The dried powder was pre-calcined at $500{ }^{\circ} \mathrm{C}$ for two hours in an air atmosphere and subsequently calcined at $1000^{\circ} \mathrm{C}, 1200{ }^{\circ} \mathrm{C}$, or $1400{ }^{\circ} \mathrm{C}$ for four hours. The catalyst prepared via the precipitation method is referred to as "C-(number)", with the numbers in parentheses indicating the calcination temperature. 
The procedure for preparing the $\mathrm{Sr}$ hexaaluminate $\left(\mathrm{Sr}_{0.8} \mathrm{La}_{0.2} \mathrm{MnAl}_{11} \mathrm{O}_{19}\right)$ catalyst via the sol-gel process is as follows [24]: firstly, $10 \mathrm{~g}$ of aluminum isopropoxide (99.99\%, Aldrich, Saint Louis, MO, USA) and Sr metal (99\%, Aldrich, Saint Louis, MO, USA) calculated according to the composition requirements were prepared in an $\mathrm{N}_{2}$ atmosphere glove box. Subsequently, $100 \mathrm{~mL}$ of 1-buthanol (99.8\%, Aldrich, Saint Louis, MO, USA) was continuously added through a Schlenk line in an $\mathrm{N}_{2}$ atmosphere for five hours. Hydrolysis proceeded by slowly adding an $\mathrm{Mn}$ nitrate and La nitrate solution to the abovementioned solution via a dropwise approach. The resulting gel solution was aged for $12 \mathrm{~h}$ while being maintained at $80{ }^{\circ} \mathrm{C}$ in air and vigorously stirred. The aged gel was dried in a rotary vacuum evaporator. The fully dried material was ground to a powder having a size of $250 \mu \mathrm{m}$ or less. Thereafter, the mixture was calcined at $500{ }^{\circ} \mathrm{C}$ for two hours and then calcined at $1000^{\circ} \mathrm{C}, 1200^{\circ} \mathrm{C}$, or $1400^{\circ} \mathrm{C}$ for four hours. The catalyst prepared via the sol-gel process is termed "S-(number)", and the numbers in parentheses indicate the calcination temperature, as above.

In order to verify the repeatability of the catalyst used in this study, it was necessary to use a shaped catalyst. In this regard, the C-1200 catalyst was mixed with a binder. Subsequently, a pellet-type catalyst with a diameter of $2 \mathrm{~mm}$ and a length of $3 \mathrm{~mm}$ was prepared via extrusion of a mixture of the powder catalyst and the binder.

\subsection{Characterization of Catalysts}

The $\mathrm{N}_{2}$ adsorption isotherms were analyzed using a BELSORP mini II (BEL, Toyonaka, Japan). All samples were dried, and $0.1 \mathrm{~g}$ of each sample was loaded into the cell. A pretreatment was carried out at $200{ }^{\circ} \mathrm{C}$ under a vacuum for six hours. An adsorption isotherm was obtained by measuring the amount of $\mathrm{N}_{2}$ gas adsorbed across a range of pressures from $10^{-3}$ to 760 Torr at a constant temperature of $-196{ }^{\circ} \mathrm{C}$. Conversely, a desorption isotherm was achieved by measuring $\mathrm{N}_{2}$ gas removed while the pressure was reduced to $10^{-3}$ Torr. Surface area and pore size distribution of the $M M Z_{Y}$ samples were determined using the Brunauer-Emmett-Teller (BET) and Barret-Joyner-Halenda (BJH) methods, respectively.

X-ray fluorescence (XRF) was measured using a ZSX Primus (Rigaku, Tokyo, Japan) to determine the composition of the prepared catalysts. The crystalline structure of the catalyst was examined by low-angle X-ray diffraction (XRD) using a Rigaku D/MAX-2200V diffractometer (Tokyo, Japan) with a built-in Cu tube. Reduction of the collected data was then carried out using the JADE program.

BEL-CAT-B (BEL, Toyonaka, Japan) was used for temperature-programmed reduction (TPR) of hydrogen to analyze the reducibility of the catalysts. The catalyst sample $(0.02 \mathrm{~g})$ was outgassed at $200{ }^{\circ} \mathrm{C}$ under a helium flow $\left(50 \mathrm{~mL} / \mathrm{min}\right.$ ) for two hours, and then cooled to $50^{\circ} \mathrm{C}$. Subsequently, the temperature was increased to $800{ }^{\circ} \mathrm{C}$ at a rate of $10^{\circ} \mathrm{C} / \mathrm{min}$, and the consumed $\mathrm{H}_{2}$ was measured using a thermal conductivity detector.

For analysis of the binding energy of Mn2p and Ols, X-ray photoelectron spectroscopy (XPS, MultiLab 2000, Thermo Fisher Scientific, Waltham, MA, USA) was employed. The C1s peak (binding energy $=284.5 \mathrm{eV}$ ) was used as a reference for the binding energy calibration.

\subsection{Thermal and Catalytic Decomposition of Liquid Monopropellants}

The composition of the ADN-based liquid monopropellant was $65 \%$ ADN, $10 \%$ water, $20 \%$ methanol, and $5 \%$ ammonia. In addition, a $70 \%$ aqueous HAN solution was used as a model reactant for the HAN-based liquid monopropellant. A catalyst evaluation test was performed in a custom-made batch-type reactor (Figure 9) with reference to the literature [32]. The decomposition reaction procedure of the liquid monopropellants is as follows: firstly, $80 \mathrm{mg}$ of $\mathrm{Sr}$ hexaaluminate powder catalyst was loaded into a sample holder inside the reactor, and $50 \mu \mathrm{L}$ of a single-liquid propellant was added using a micropipette. Thtable e temperature of the sample holder inside the reactor was raised to $200{ }^{\circ} \mathrm{C}$ at a rate of $10{ }^{\circ} \mathrm{C} / \mathrm{min}$. At this time, the pressure and the temperature on the gas phase were recorded ten times per second. The reaction activity was evaluated using the decomposition onset temperature $\left(\mathrm{T}_{\mathrm{dec}}\right)$, which is the temperature at which the inflection point of the temperature 
curve starts. The procedure of thermal decomposition was the same as the catalytic decomposition experiment except that no catalyst was loaded inside the reactor.
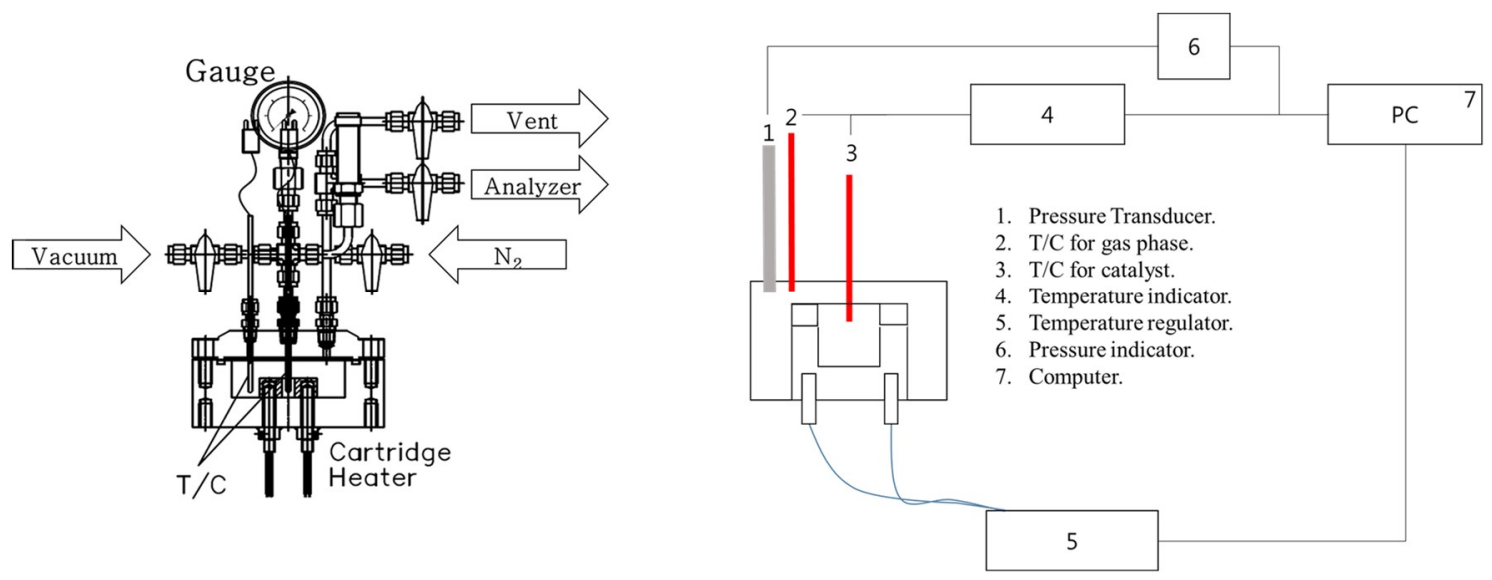

Figure 9. Reaction system for the catalytic decomposition of liquid monopropellants.

\section{Conclusions}

The synthesis procedure and the heat-treatment temperature had a great influence on the physicochemical properties of the Sr hexaaluminates. The surface area of hexaaluminate synthesized via the coprecipitation method was greater than that of hexaaluminate synthesized via the sol-gel process and calcined at the same temperature of $1200{ }^{\circ} \mathrm{C}$ or more. This results from the sintering of $\alpha-\mathrm{Al}_{2} \mathrm{O}_{3}$ on the hexaaluminate synthesized via the sol-gel process, which could not be observed on the catalysts synthesized via the coprecipitation method.

The hexaaluminate synthesized via coprecipitation showed a lower decomposition onset temperature during the decomposition of ADN- and HAN-based liquid monopropellants in comparison with the catalysts synthesized via the sol-gel process which calcined at the same temperature of $1200{ }^{\circ} \mathrm{C}$ or more. This is attributed to the differences in the $\mathrm{Mn}^{3+}$ concentration, as well as in surface area, between the two hexaaluminates. In conclusion, the hexaaluminate synthesized via coprecipitation which calcined above $1200{ }^{\circ} \mathrm{C}$ showed high activity during the decomposition of the energetic ionic liquid monopropellant compared with the hexaaluminate synthesized via the sol-gel process.

Author Contributions: S.H. (Sunghoon Hong), S.H. (Sujeong Heo), and W.K. performed the experiments; S.H. (Sunghoon Hong), S.H. (Sujeong Heo), W.K., Y.M.J., Y.-K.P., and J.-K.J. collected and analyzed the data; S.H. (Sunghoon Hong), Y.-K.P., and J.-K.J. wrote the manuscript.

Funding: This research was supported by the Basic Science Research Program through the National Research Foundation of Korea (NRF) funded by the Ministry of Science, ICT, \& Future Planning (NRF-2016M1A3A3A02017723 and 2017M1A3A3A02016209).

Conflicts of Interest: The authors declare no conflicts of interest.

\section{References}

1. Courtheoux, L.; Gautron, E.; Rossignol, S.; Kappenstein, C. Transformation of platinum supported on silicon-doped alumina during the catalytic decomposition of energetic ionic liquid. J. Catal. 2005, 232, 10-18. [CrossRef]

2. Amrousse, R.; Hori, K.; Fetimi, W.; Farhat, K. HAN and ADN as liquid ionic monopropellants: Thermal and catalytic decomposition processes. Appl. Catal. B Environ. 2012, 127, 121-128. [CrossRef]

3. Farshchi, M.; Vaezi, V.; Shaw, B.D. Studies of HAN-based monopropellant droplet combustion. Combust. Sci. Technol. 2002, 174, 71-97. [CrossRef] 
4. Amrousse, R.; Katsumi, T.; Azuma, N.; Hori, K. Hydroxylammonium nitrate (HAN)-based green propellant as alternative energy resource for potential hydrazine substitution: From lab scale to pilot plant scale-up. Combust. Flame 2017, 176, 334-348. [CrossRef]

5. Zhang, T.; Li, G.; Yu, Y.; Sun, Z.; Wang, M.; Chen, J. Numerical simulation of ammonium dinitramide (ADN)-based non-toxic aerospace propellant decomposition and combustion in a monopropellant thruster. Energy Convers. Manag. 2014, 87, 965-974. [CrossRef]

6. Agnihotri, R.; Oommen, C. Cerium oxide based active catalyst for hydroxylammonium nitrate (HAN) fueled monopropellant thrusters. RSC Adv. 2018, 8, 22293-22302. [CrossRef]

7. Lee, H.; Litzing, T.A. Chemical kinetic study of HAN decomposition. Combust. Flame 2003, 135, 151-169. [CrossRef]

8. Kleimark, J.; Delanoë, R.; Demairé, A.; Brinck, T. Ionization of ammonium dinitramide: Decomposition pathways and ionization products. Theor. Chem. Acc. 2013, 132, 1-9. [CrossRef]

9. Courthéoux, L.; Amariei, D.; Rossignol, S.; Kappenstein, C. Thermal and catalytic decomposition of HNF and HAN liquid ionic as propellants. Appl. Catal. B Environ. 2006, 62, 217-225. [CrossRef]

10. Vyazovkin, S.; Wight, C.A. Ammonium dinitramide: Kinetics and mechanism of thermal decomposition. J. Phys. Chem. A 1997, 101, 5653-5658. [CrossRef]

11. Gronland, T.A.; Westerberg, B.; Bergman, G.; Anflo, K.; Brandt, J.; Lyckfeldt, O.; Agrell, J.; Ersson, A.; Jaras, S.; Boutonnet, M.; et al. Reactor for Decomposition of Ammonium Dinitramide-Based Liquid Monopropellants and Process for the Decomposition. U.S. Patent 7137244B2, 21 November 2006.

12. Osman, A.I.; Abu-Dahrieh, J.K.; McLaren, M.; Laffir, F.; Rooney, D.W. Characterisation of Robust Combustion Catalyst from Aluminium Foil Waste. Chem. Sel. 2018, 3, 1545-1550. [CrossRef]

13. Giannikos, A.; Frantzis, A.D.; Pliangos, C.; Bebelis, S.; Vayenas, C.G. Electrochemical promotion of $\mathrm{CH}_{4}$ oxidation on Pd. Ionics 1998, 4, 53-60. [CrossRef]

14. Nishino, A. Household appliances using catalysis. Catal. Today 1991, 10, 107-118. [CrossRef]

15. Machida, M.; Eguchi, K.; Arai, H. Catalytic properties of $\mathrm{BaMAl}_{11} \mathrm{O}_{19-\alpha}(\mathrm{M}=\mathrm{Cr}, \mathrm{Mn}, \mathrm{Fe}, \mathrm{Co}$, and Ni) for high-temperature catalytic combustion. J. Catal. 1989, 120, 377-386. [CrossRef]

16. Machida, M.; Eguchi, K.; Arai, H. Effect of structural modification on the catalytic property of Mn-substituted hexaaluminates. J. Catal. 1990, 123, 477-485. [CrossRef]

17. Yeh, T.F.; Lee, H.G.; Chu, K.S.; Wang, C.B. Characterization and catalytic combustion of methane over hexaaluminates. Mater. Sci. Eng. A 2004, 384, 324-330. [CrossRef]

18. Hong, S.; Heo, S.; Li, C.; Jeon, B.K.; Kim, J.M.; Jo, Y.M.; Kim, W.; Jeon, J.K. Preparation of Mesoporous CuCe-Based Ternary Metal Oxide by Nano-Replication and Its Application to Decomposition of Liquid Monopropellant. J. Nanosci. Nanotechnol. 2018, 18, 1427-1430. [CrossRef]

19. Thommes, M.; Kaneko, K.; Neimark, A.V.; Olivier, J.P.; Rodriguez-Reinoso, F.; Rouquerol, J.; Sing, K.S.W. Physisorption of gases, with special reference to the evaluation of surface area and pore size distribution (IUPAC Technical Report). Pure Appl. Chem. 2015, 87, 1051-1069. [CrossRef]

20. Tian, M.; Wang, X.D.; Zhang, T. Hexaaluminates: A review of the structure, synthesis and catalytic performance. Catal. Sci. Technol. 2016, 6, 1984-2004. [CrossRef]

21. Tabesh, S.; Davar, F.; Loghman-Estarki, M.R. Preparation of $\gamma-\mathrm{Al}_{2} \mathrm{O}_{3}$ nanoparticles using modified sol-gel method and its use for the adsorption of lead and cadmium ions. J. Alloys Compd. 2018, 730, 441-449. [CrossRef]

22. Jbara, A.S.; Othaman, Z.; Saeed, M.A. Structural, morphological and optical investigations of $\theta-\mathrm{Al}_{2} \mathrm{O}_{3}$ ultrafine powder. J. Alloys Compd. 2017, 718, 1-6. [CrossRef]

23. Kim, S.; Lee, D.W.; Lee, J.Y.; Eom, H.; Lee, H.J.; Cho, I.; Lee, K.Y. Catalytic combustion of methane in simulated PSA offgas over Mn-substituted La-Sr-hexaaluminate $\left(\mathrm{La}_{\mathrm{x}} \mathrm{Sr}_{1-\mathrm{x}} \mathrm{MnAl}_{11} \mathrm{O}_{19}\right)$. J. Mol. Catal. A Chem. 2011, 335, 60-64. [CrossRef]

24. Son, J.M.; Woo, S.I. A study on physical properties and catalytic combustion of methane of Sr hexaaluminate prepared using 1-butanol and ethylene glycol. Korean Chem. Eng. Res. 2007, 45, 209-214.

25. Li, S.; Wang, X. Catalytic combustion of methane over Mn-substituted Ba-La-hexaaluminate nanoparticles. J. Alloys Compd. 2007, 432, 333-337. [CrossRef]

26. Woo, S.I.; Kang, S.K.; Sohn, J.M. Effect of water content in the precursor solution on the catalytic property and stability of $\mathrm{Sr}_{0.8} \mathrm{La}_{0.2} \mathrm{MnAl}_{11} \mathrm{O}_{19}$ high-temperature combustion catalyst. Appl. Catal. B Environ. 1998, 18, 317-324. 
27. Wang, W.; Yuan, F.; Niu, X.; Zhu, Y. Preparation of Pd supported on La(Sr)-Mn-O Perovskite by microwave irradiation Mmethod and its catalytic performances for the methane combustion. Sci. Rep. 2016, 6, 1-10.

28. Kim, G.; Kim, J.M.; Lee, C.H.; Han, J.; Jeong, B.H.; Jeong, J.K. Catalytic Properties of Nanoporous manganese oxides in decomposition of high-purity hydrogen peroxide. J. Nanosci. Nanotechnol. 2016, 16, 9153-9159. [CrossRef]

29. Park, G.O.; Shon, J.K.; Kim, Y.H.; Kim, J.M. Synthesis of ordered mesoporous manganese oxides with various oxidation states. J. Nanosci. Nanotechnol. 2015, 15, 2441-2445. [CrossRef]

30. Esparza, A.A.; Ferguson, R.E.; Choudhuri, A.; Love, N.D.; Shafirovich, E. Thermoanalytical studies on the thermal and catalytic decomposition of aqueous hydroxylammonium nitrate solution. Combust. Flame 2018, 193, 417-423. [CrossRef]

31. Jang, I.J.; Jang, Y.B.; Shin, H.S.; Shin, N.R.; Kim, S.K.; Yu, M.J.; Cho, S.J. Preparation and characterization of lanthanum hexaaluminate granule for catalytic application in aerospace technology. In Proceedings of the 18th International Conference on Composite Materials, Jeju, Korea, 21-26 August 2011.

32. Eloirdi, R.; Rossignol, S.; Kappenstein, C.; Duprez, D. Design and use of a batch reactor for catalytic decomposition of propellants. J. Propuls. Power 2003, 19, 213-219. [CrossRef]

(C) 2019 by the authors. Licensee MDPI, Basel, Switzerland. This article is an open access article distributed under the terms and conditions of the Creative Commons Attribution (CC BY) license (http:/ / creativecommons.org/licenses/by/4.0/). 